\title{
Amalan Pengajaran Guru di Pondok Bantan, Nakhon Si Thammarat, Thailand
}

\author{
Pedagogical Practices in Pondok Bantan, Nakhon Si Thammarat, Thailand \\ HAZIYAH HUSSIN*, MOHD ADERI CHE NOH, MUHAMAD RAZAK IDRIS, FARID MAT \\ ZAIN, HAMDI ISHAK, SALAMIAH AB. GHANI \& ABDULROYA PANAEMALAE ${ }^{1}$
}

\begin{abstract}
Historically, Pondok Bantan is a traditional Islamic educational institution that applies teacher-centered approach in teaching and learning programmes based on religious texts. However, in line with the changes in needs and time of society, the Pondok is now adopting Thai national curriculum which at the same time integrate with religious education curriculum based on the traditional (turath) texts of Malay scholars. The diversity in its educational curriculum components perceived as a strength for Pondok Bantan but becomes a challenge to the teachers' ability to implement and ensure the teaching curriculum adopted is efficient for the holistic development of the students. Therefore, this study aims to identify attitudes and approaches applied by Pondok Bantan teachers' in their teaching activities and the level of teaching aids application. The study applies quantitative research method involving 43 respondents among the teachers of Pondok Bantan. Data are obtained from the questionnaires and then analyzed using the descriptive statistics tehnique to measure the frequency, ranges, mean and standard deviation. The findings show that the teachers' attitudes and practices toward teaching activities are high either before of the classrooms. However, the use of teaching aids need to be improved in the future by the teachers and the management of Pondok Bantan since its practices are in between moderate and high level.
\end{abstract}

Keywords: pondok, Pondok Bantan, religious education, Southern Thailand, teaching

\footnotetext{
1 Haziyah Hussin* (corresponding author), Ph.D., senior lecturer at Centre for Islamic Heritage Sustainability, Faculty of Islamic Studies, Universiti Kebangsaan Malaysia, 43600 BANGI, Selangor, Malaysia, email: haziyah@ukm.edu.my; Muhamad Razak Idris, Ph.D., senior lecturer at Centre for Akidah and Global Peace, Faculty of Islamic Studies, Universiti Kebangsaan Malaysia, 43600 BANGI, Selangor, Malaysia, email:mrazak@ukm.edu.my; Farid Mat Zain, Ph.D., senior lecturer at Centre of Middle East and Nusantara, Faculty of Islamic Studies, Universiti Kebangsaan Malaysia, 43600 BANGI, Salangor, Malaysia, email: farid@ukm.edu.my; Hamdi Ishak, Ph.D, senior lecturer at Centre for Islamic Heritage Sustainability, Faculty of Islamic Studies, Universiti Kebangsaan Malaysia, 43600 BANGI, Selangor, Malaysia, email: hamdi@ukm.edu.my; Salamiah Ab. Ghani, MA, language teacher at Faculty of Islamic Studies, Universiti Kebangsaan Malaysia, 43600 BANGI, Salangor, Malaysia, email: salma@ukm.edu.my; Mohd Aderi Che Noh, Ph.D., professor at Faculty of Social Science and Humanities, Universiti Pendidikan Sultan Idris, 35900 TANJUNG MALIM, Perak, Malaysia, email: aderi@fsk.upsi.edu.my; Abdulroya Panaemalae, M.A., lecturer at Faculty of Liberal Arts, Walailak University, 222 Thaiburi, Thasala DISTRICT NAKHON SI THAMMARAT 80161 Thailand, email: pabdul.razak09@gmail.com.
} 
Pendidikan Islam di Thailand khususnya di Selatan Thailand melaksanakan tiga jenis sekolah. Pertama, sekolah di bawah seliaan dan tajaan kerajaan yang menawarkan pendidikan Islam dalam kurikulum kebangsaan dan menggunakan bahasa Thailand sebagai bahasa pengantar. Kedua, sekolah Islam swasta atau dinamakan juga sebagai madrasah yang menawarkan kurikulum pendidikan Islam di samping subjek-subjek umu yang lain seperti sains, matematik dan bahasa Inggeris. Biasanya madrasah ini berdaftar dengan kerajaan. Jenis sekolah yang ketiga ialah pondok yang menawarkan struktur pengajian yang mudah dan terletak bersebelahan dengan masjid (Anthony 2007). Ia dinamakan sebagai sekolah pondok kerana sekolah ini merupakan pusat pengajian yang dibangunkan oleh perseorangan yang berhasrat mengajar ilmu agama kepada murid-murid. Justeru ia dibina berdekatan dengan tempat tinggalnya. Murid-murid pula membina rumah kecil yang dipanggil 'pondok' di kawasan yang sama sebagai tempat kediaman sepanjang pengajian. Sistem pengajian ini bersifat mandiri, tiada syarat kemasukan mahu pun had umur, penggunaan kitab-kitab tradisi pengajian Islam sama ada karya berbahasa Arab atau karya ulama tempatan, pembacaan dan ulasan kandungan kitab oleh guru serta tiada pentaksiran formal. Manakala aspek pembangunan sahsiah pula berlaku secara tidak langsung melalui rutin harian murid dan interaksi mereka dengan guru-guru. Pondok juga merupakan salah satu daripada budaya umat Islam yang tidak dapat dipisahkan dalam kehidupan seharian (Hasan 2002; Kamaruzzaman 2015). Sistem sekolah agama ini sangat penting dalam komuniti muslim Thai bagi memelihara keluhuran akhlak anak-anak, memugar pengetahuan agama Islam selain melestarikan budaya Melayu.

Maahad Misbah al-Din atau Prateepsassana Islamic School yang lebih dikenali sebagai Pondok Bantan merupakan sekolah yang menawarkan kurikulum bersepadu, menggabungkan kurikulum kebangsaan, pendidikan Islam dan pengajian turath. Ia terletak di utara bandar Nakhon Si Thammarat, salah sebuah wilayah di Selatan Thai. Ia dinamakan Pondok Bantan kerana dinisbahkan kepada kampung Ban Tan (Ban bermaksud rumah manakala Tan atau tal bermaksud kelapa laut. Pada suatu ketika kawasan ini penuh dengan pokok kelapa laut). Pusat pengajian bersejarah ini diasaskan oleh Tuan Guru Haji Yaakob bin Abdul Rauf (1900-1973), pada tahun 1939. Ciri pengajian tradisional pondok ini mengalami transformasi apabila ia didaftarkan di bawah Kementerian Pendidikan Thailand pada tahun 1971 (Hasan 2002). Selepas itu, sistem pendidikannya menerima pakai kurikulum kebangsaan. Perubahan ini sejajar dengan tuntutan dasar negara Thailand yang mula diperkenalkan pada tahun 1960 di mana institusi pondok digalakkan mendaftar pondok mereka dengan pihak kerajaan di bawah status Sekolah Agama Islam Swasta (Rongrian Aikachon Son Sasna Islam). Malah Kementerian Pendidikan Thai telah memajukan pendidikan di wilayah di Selatan Thai selari dengan program kemajuan pendidikan yang digunakan di seluruh negara (Hasan 2002). Pondok Bantan menjadi kebanggaan masyarakat Islam di Nakhon $\mathrm{Si}$ Thammarat bahkan menjadi mercu tanda keupayaan pendidikan Islam setanding dengan pendidikan moden Thai.

Pondok Bantan menawarkan dua aliran kurikulum iaitu aliran akademik atau kebangsaan dan aliran agama yang menjadi tradisi utama pengajian pondok, dari tingkatan satu hingga tingkatan enam. Subjek akademik merangkumi bahasa Thai, bahasa Inggeris, Sains, Matematik, geografi, Pendidikan Jasmani dan lain-lain (Karim et. al 2019). Antara subjek agama yang diajar di pondok ini ialah al-Quran, tafsir, hadith, fiqh, tauhid, bahasa Arab, tulisan jawi dan bahasa Melayu. Silibus agama ditentukan dan diselaraskan oleh ketua subjek dan Jawatankuasa Akademik Pondok Bantan sendiri. Buku-buku agama yang digunakan sebagai teks pula adalah dalam bahasa Arab dan sebahagiannya dalam bahasa Melayu tulisan Jawi. Penggunaan kitab Melayu Jawi ini menjadi sumber utama ilmu Islam bahkan ciri penting kepada pendidikan Islam tradisional. Ia juga menjadi medium transmisi pemikiran ulama Timur Tengah ke Nusantara (Faudzinaim 2012). Kebanyakan buku ini ialah hasil karya ulama Patani seperti Syeikh Daud Fatoni dan Syeikh Ahmad Fatani (Hasan 2002). Meskipun begitu, bahasa Thai digunakan sebagai bahasa pengantar pengajian. Guru-guru membaca teks Arab atau teks Melayu Jawi, kemudian menghuraikan atau menterjemahkannya ke bahasa Thai. Antara kitab pengajian 
tersebut ialah kitab Sabil al-Muhtadiin, Matla' al-Badrain, Jawhar al-Mauhub, Tafsir Nur al-Ihsan dan Riyadh al-Salihin (Salamiah et. al 2019).

Sebagaimana sekolah-sekolah Islam yang lain di Selatan Thai, Pondok Bantan juga menghadapi beberapa kekangan seperti kemudahan infrastruktur dan fasiliti yang terhad, peruntukan kewangan kerajaan yang sedikit, kesulitan mendapatkan pendekatan bersepadu dalam sistem pendidikan serta ketidakseragaman kurikulum agama kerana ia diatur oleh tafsiran teks agama tidak ada keperluan mematuhi (New Mandala 2013). Hal ini dtegaskan juga oleh Ibrahem (2018), kurikulum agama ditentukan sendiri oleh guru dan panitia mata pelajaran Pondok Bantan. Keadaan ini menyukarkan guru untuk mendapatkan panduan yang standard dalam melaksanakan proses pengajaran dan pembelajaran. Meskipun begitu, sekolah-sekolah Islam ini mendapat sambutan yang amat tinggi kalangan masyarakat malah jumlah kemasukan pelajar ke sekolah aliran ini lebih tinggi berbanding sekolah kerajaan. Faktor utama pemilihan ini dinyatakan oleh Wisalaporn dalam Chatthida et. al (2019) adalah kepercayaan dan keimanan masyarakat terhadap Islam: "...due to their belief or faith in Islam that is like a framework or guidelines to improve, nurture and create good citizenship, together with the educational management environment that is conducive to the education of the Muslims". Pondok Bantan juga mendapat tempat dalam masyarakat muslim Thailand. Jumlah pelajarnya meningkat saban tahun dan mencapai 1,800 orang pada tahun 2018. Mereka bukan hanya berasal dari Nakhon Si Thammarat bahkan dari wilayah-wilayah lain; Satun, Songkla, Patani, Yala dan Narathiwat (Nor Asyikin 2018). Ternyata Pondok Bantan menjadi hub pendidikan Islam di Thailand.

Sehubungan itu, kajian tentang pengamalan pengajaran dan pembelajaran (PdP) guru di pondok ini amat wajar dilakukan bagi mengenalpasti sikap dan kesediaan guru, mengkaji pendekatan pengajaran yang diaplikasi oleh guru pada sesi permulaan, perkembangan dan penutup serta penggunaan bahan bantu mengajar. Hasil kajian ini signifikan bagi memastikan keberkesanan PdP dan kemenjadian murid dalam jangka masa yang panjang. Ia juga dapat digunakan sebagai input untuk menambah baik sistem pendidikan Pondok Bantan khususnya perlaksanaan pengajaran serta memantapkan tahap profesionalisme guru.

\section{Metode Kajian}

Kajian ini ialah kajian tinjauan ke atas amalan pengajaran guru Pondok Bantan di Nakhon Si Thammarat, Thailand. Pemilihan pondok ini adalah disebabkan keunikan kurikulumnya yang bersepadu, kedudukannya dalam masyarakat sebagai sebuah sekolah berprestij, dilengkapi dengan banyak kemudahan dan mendapat tajaan antarabangsa (New Mandala 2013). Data dikumpulkan dengan menggunakan instrumen soal selidik. Soal selidik mengandungi tiga bahagian. Bahagian A tentang maklumat demografi responden, bahagian B yang berkaitan dengan sikap guru dalam pengajaran dan bahagian $C$ pula mengandungi empat konstruk tentang amalan pengajaran guru iaitu: (i) permulaan pengajaran; (ii) perkembangan pengajaran; (iii) penutup pengajaran; dan (iv) alat bantu mengajar guru. Seramai 43 orang guru akademik dan guru agama di Pondok Bantan dipilih dengan persampelan secara bertujuan sebagai responden iaitu mewakili $40 \%$ daripada jumlah guru. Selain itu, instrumen temu bual secara separa berstruktur dengan Ketua Panitia Bahasa Arab dan guru agama kanan dilaksanakan serta analisis dokumen bagi memperoleh data tentang sistem pendidikan Pondok Bantan dan kedudukan institusi ini.

Data kajian dianalisis menggunakan perisian IBM Statistical Package for Social Science (SPSS) Versi 25.0. Kaedah statistik deskriptif digunakan untuk menentukan tahap amalan pengajaran guru berdasarkan frekuensi, peratusan, min dan sisihan piawai. Jadual interpretasi terhadap nilai min adalah berdasarkan jadual interpretasi yang dirumuskan oleh Nunnally (1978). Interpretasi ini akan dihuraikan pada setiap sesi pengajaran guru iaitu sesi permulaan, perkembangan, penutup dan alat bantu mengajar. 
Jadual 1: Interpretasi Nilai Skor Min

\begin{tabular}{cc}
\hline Nilai Skor Min & $\begin{array}{c}\text { Interpretasi Tahap Amalan } \\
\text { Pengajaran }\end{array}$ \\
\hline $4.01-5.00$ & Tinggi \\
$3.01-4.00$ & Sederhana Tinggi \\
$2.01-3.00$ & Sederhana Rendah \\
$1.01-2.00$ & Sangat Rendah \\
\hline & Sumber: Nunnally (1978)
\end{tabular}

\section{Dapatan Kajian dan Perbincangan}

Jumlah guru di Pondok Bantan adalah seramai 100 orang; 30 orang guru agama dan 70 orang guru akademik. Semua guru beragama Islam kecuali lima orang sahaja, iaitu empat orang guru beragama Buddha dan seorang beragama Kristian iaitu guru mata pelajaran bahasa Inggeris yang berasal dari Filipina. Guru-guru agama di pondok Bantan ini adalah lepasan dari pelbagai institusi pendidikan seperti Universiti al-Azhar Mesir, Universiti Sains Islam Malaysia, dan beberapa universiti tempatan yang lain. Selain itu ada juga lepasan pondok seperti Pondok Bantan sendiri dan pondok-pondok di Selatan Thai khususnya di Patani. Majoriti guru akademik pula adalah lepasan universiti tempatan. Selain itu, sebilangan guru lepasan pondok yang tidak memiliki apa-apa sijil akademik tetapi mereka diterima sebagai tenaga pengajar berdasarkan kepercayaan pihak pentadbir sekolah terhadap mereka dan pengalaman yang dimiliki. Guruguru ini mesti memiliki tauliah yang dikeluarkan oleh Kementerian Pendidikan Thai dan tauliah ini perlu diperbaharu setiap lima tahun. Bagi menjamin kualiti pengajaran, guru-guru perlu mengikuti latihan dan kursus berkaitan pengajaran dan pembelajaran sebanyak 20 jam setahun (Abdul Rahman Laici 2018).

Seramai 43 orang guru Pondok Bantan, Nakhon Si Thammarat terlibat dalam kajian ini dan mereka terdiri daripada pelbagai latar belakang jantina, pengalaman mengajar, kelulusan ikhtisas, kelulusan akademik dan bilangan waktu mengajar dalam seminggu. Profil demografi kajian adalah seperti Jadual 2 .

Jadual 2: Profil Demografi Kajian

\begin{tabular}{lcc}
\hline \multicolumn{1}{c}{ Demografi } & Kekerapan & Peratusan \\
\hline Jantina & & \\
Lelaki & 21 & $48.8 \%$ \\
$\quad$ Perempuan & 22 & $51.2 \%$ \\
Pengalaman mengajar & & \\
0 - 5 tahun & 4 & $9.3 \%$ \\
6-10 tahun & 8 & $18.6 \%$ \\
11 - 15 tahun & 2 & $4.7 \%$ \\
16 - 20 tahun & 3 & $7.0 \%$ \\
21 tahun ke atas & 3 & $7.0 \%$ \\
$\quad$ Lain-lain & 23 & $53.5 \%$ \\
Kelulusan Ikhtisas & 9 & \\
$\quad$ Diploma Pendidikan & 24 & $20.9 \%$ \\
$\quad$ Sijil Perguruan & 10 & $55.8 \%$ \\
$\quad$ Lain-lain & & $23.3 \%$ \\
Kelulusan Akademik Tertinggi & 0 & 0 \\
$\quad$ Doktor Falsafah & 2 & $4.7 \%$ \\
$\quad$ Sarjana & 32 & $74.4 \%$ \\
$\quad$ Sarjana Muda/ Pendidikan & 9 & $20.9 \%$ \\
$\quad$ Lain-lain & & \\
Bilangan Waktu mengajar & 1 & $2.3 \%$ \\
0 - 5 waktu & &
\end{tabular}




\begin{tabular}{lcc}
\hline $6-10$ waktu & 1 & $2.3 \%$ \\
$11-15$ waktu & 7 & $16.3 \%$ \\
$16-20$ waktu & 8 & $18.6 \%$ \\
21 ke atas & 13 & $30.2 \%$ \\
Lain-lain & 13 & $30.2 \%$ \\
\hline
\end{tabular}

Sumber: Soal selidik 2018

Jadual 2 menunjukkan bahawa terdapat seramai 21 orang (48.8\%) guru lelaki dan seramai 22 orang (51.2\%) guru perempuan. Pengalaman mengajar didapati hanya 4 orang $(9.3 \%)$ berpengalaman kurang dari 5 tahun, 8 orang $(18.6 \%)$ guru mempunyai pengalaman antara 6-10 tahun, 2 orang (4.7\%) berpengalaman antara 11-15 tahun, 3 orang $(7.0 \%)$ berpengalaman 16-20 tahun, 3 orang (7.0\%) berpengalaman 21 tahun ke atas dan seramai 23 orang (53.5\%) lain-lain. Seterusnya aspek kelulusan ikhtisas menunjukkan seramai 9 orang (20.9\%) guru mempunyai diploma pendidikan, seramai 24 orang (55.8\%) mempunyai sijil perguruan dan seramai 10 orang (23.3\%) lain-lain ikhtisas. Lain-lain ikhtisas merujuk kepada tauliah kerajaan kepada guru lepasan thanawiyyah. Berdasarkan kelulusan akademik tertinggi, kajian menunjukkan dua orang (4.7\%) guru kelulusan sarjana, seramai 32 orang $(74.4 \%)$ guru berkelulusan Sarjana Muda atau Pendidikan dan seramai 9 orang (20.9\%) guru lain-lain. Manakala bilangan waktu mengajar pula menunjukkan hanya seorang guru $(2.3 \%)$ masingmasing mempunyai bilangan waktu di bawah lima waktu dan mempunyai bilangan waktu antara 6-10 waktu, seramai 7 orang (16.3\%) mempunyai bilangan waktu antara 11-15 waktu, seramai 8 orang (18.6\%) mempunyai bilangan waktu antara 16-20 waktu, seramai 13 orang (30.2\%) mempunyai bilang waktu 21 waktu ke atas dan 13 orang (30.2\%) lain-lain.

\section{Sikap Guru Dalam Pengajaran}

Tujuan pendidikan ialah pembentukan akhlak dan rohani selain matlamat kebendaan. Oleh itu, guru perlu ada personaliti, sahsiah dan sikap yang mulia supaya menjadi contoh dan mempengaruhi murid. Ab. Halim \& M. Khairulazman (2010) merumuskan pandangan sarjanasarjana Muslim tentang beberapa sifat, karakter, sikap yang perlu ada pada seorang guru, iaitu ikhlas, sikap kehidupan dan pembawaan yang jelas, zuhud dalam penyampaian pelajaran kerana mencari keredhaan Allah SWT; rasa tanggungjawab dan kasih sayang terhadap murid serta memberi nasihat dan peringatan. Malah, sifat-sifat keperibadian yang unggul, ketokohan dan perwatakan sempurna menjadi faktor keberkesanan dalam menyampaikan ilmu pengetahuan (Abdullah Ishak 1989) dan menjadi contoh teladan kepada pelajar seterusnya mengamalkannya dalam kehidupan seharian (Sofiah et. al 2016). Dalam proses pendidikan juga, guru perlu prihatin terhadap kemampuan muridnya dalam menerima ilmu dan maklumat yang disampaikan. Hal ini untuk mengelakkan daripada berlaku salah faham dan silap memahami, memikir atau mempraktikkan ilmu tersebut. Data berikut menunjukkan skor sikap guru Pondok Bantan dalam pengajaran:

Jadual 3: Sikap Guru dalam Pengajaran

\begin{tabular}{llcccccccc}
\hline No & \multicolumn{1}{c}{ Item } & STS & TS & KS & S & SS & $\begin{array}{c}\text { Min } \\
\text { Sisihan Interpretasi } \\
\text { piawai }\end{array}$ \\
\hline 1. & $\begin{array}{l}\text { Saya seronok } \\
\text { mengajar }\end{array}$ & 0 & 0 & 3 & 15 & 25 & 4.51 & 0.631 & Tinggi \\
& $\begin{array}{l}\text { Pengajian Islam } \\
\text { Saya berusaha } \\
\text { agar pelajar }\end{array}$ & 0 & 0 & 2 & $11 \%)$ & 30 & 4.65 & 0.573 & Tinggi \\
& $(0 \%)$ & $(0 \%)$ & $(4.7 \%)$ & $(25.6 \%)$ & $(69.8 \%)$ & & &
\end{tabular}


3. Saya bangga kerana dapat mengajar

Pengajian Islam.

4. Saya berusaha agar semua pelajar saya dapat memahami pelajaran dengan baik.

5. Saya berusaha menyampaikan pengajaran secara sistematik kepada setiap pelajar.

6. Saya berusaha mengetahui tahap penguasaan setiap pelajar.

7. Saya sentiasa membuat rujukan untuk menambahkan pengetahuan.

8. Saya menghadapi masalah untuk memastikan pelajar dapat menguasai pelajaran.

9. Saya rasa adalah penting setiap pelajar diberi dorongan untuk menguasai bacaan al-Quran.

10. Saya sentiasa menggalak pelajar berjaya dalam pelajaran.

11. Saya berusaha mempertingkatkan kualiti pengajaran.

12. Saya sentiasa berusaha merancang pengajaran.

13. Kadangkala saya merasa kurang bersemangat melihat kebanyakan prestasi pelajar lemah.

$\begin{array}{cc}0 & 0 \\ (0 \%) & (0 \%)\end{array}$

$\begin{array}{cccccccr}0 & 0 & 2 & 5 & 36 & 4.79 & 0.514 & \text { Tinggi } \\ (0 \%) & (0 \%) & (4.7 \%) & (11.6 \%) & (83.7 \%) & & & \end{array}$

14. Saya bersemangat untuk mengajar

$$
\begin{array}{cccccccr}
0 & 0 & 1 & 8 & 34 & 4.77 & 0.480 & \text { Tinggi } \\
(0 \%) & (0 \%) & (2.3 \%) & (18.6 \%) & (79.1 \%) & & &
\end{array}
$$

$\begin{array}{cccccccc}0 & 0 & 1 & 5 & 37 & 4.84 & 0.433 & \text { Tinggi } \\ (0 \%) & (0 \%) & (2.3 \%) & (11.6 \%) & (86.0 \%) & & & \end{array}$

$$
\begin{array}{cccccccr}
0 & 0 & 3 & 19 & 21 & 4.42 & 0.626 & \text { Tinggi } \\
(0 \%) & (0 \%) & (7.0 \%) & (44.2 \%) & (48.8 \%) & & &
\end{array}
$$

$$
\begin{array}{cccccccc}
0 & 0 & 2 & 24 & 17 & 4.35 & 0.573 & \text { Tinggi } \\
(0 \%) & (0 \%) & (4.7 \%) & (55.8 \%) & (39.5 \%) & & &
\end{array}
$$

\begin{tabular}{|c|c|c|c|c|c|c|c|}
\hline $\begin{array}{c}0 \\
(0 \%)\end{array}$ & $\begin{array}{c}0 \\
(0 \%)\end{array}$ & $\begin{array}{c}2 \\
(4.7 \%)\end{array}$ & $\begin{array}{c}10 \\
(23.3 \%)\end{array}$ & $\begin{array}{c}31 \\
(72.1 \%)\end{array}$ & 4.67 & 0.566 & Tinggi \\
\hline $\begin{array}{c}0 \\
(0 \%)\end{array}$ & $\begin{array}{c}0 \\
(0 \%)\end{array}$ & $\begin{array}{c}2 \\
(4.7 \%)\end{array}$ & $\begin{array}{c}15 \\
(34.9 \%)\end{array}$ & $\begin{array}{c}26 \\
(60.5 \%)\end{array}$ & 4.56 & 0.590 & Tinggi \\
\hline $\begin{array}{c}0 \\
(0 \%)\end{array}$ & $\begin{array}{c}0 \\
(0 \%)\end{array}$ & $\begin{array}{c}3 \\
(7.0 \%)\end{array}$ & $\begin{array}{c}21 \\
(48.8 \%)\end{array}$ & $\begin{array}{c}19 \\
(44.2 \%)\end{array}$ & 4.37 & 0.618 & Tinggi \\
\hline $\begin{array}{c}1 \\
(2.3 \%)\end{array}$ & $\begin{array}{c}8 \\
(18.6 \%)\end{array}$ & $\begin{array}{c}10 \\
(23.3 \%)\end{array}$ & $\begin{array}{c}16 \\
(37.2 \%)\end{array}$ & $\begin{array}{c}8 \\
(18.6 \%)\end{array}$ & 3.51 & 0.164 & $\begin{array}{l}\text { Sederhana } \\
\text { Tinggi }\end{array}$ \\
\hline $\begin{array}{c}0 \\
(0 \%)\end{array}$ & $\begin{array}{c}0 \\
(0 \%)\end{array}$ & $\begin{array}{c}1 \\
(2.3 \%)\end{array}$ & $\begin{array}{c}16 \\
(37.2 \%)\end{array}$ & $\begin{array}{c}26 \\
(60.5 \%)\end{array}$ & 4.58 & 0.545 & Tinggi \\
\hline
\end{tabular}

$\begin{array}{cccccccl}0 & 1 & 6 & 29 & 7 & 3.98 & 0.636 & \text { Sederhana } \\ (0 \%) & (2.3 \%) & (14.0 \%) & (67.4 \%) & (16.3 \%) & & & \text { Tinggi }\end{array}$


pelajar lemah.

15. Saya berpendapat ada pelajar yang memang tidak mempunyai keupayaan untuk menguasai pelajaran.

16. Saya sentiasa prihatin dalam pengajaran walaupun kepada pelajar yang pandai.

17. Saya sentiasa berusaha untuk mengadakan kelas tambahan bagi pelajar yang lemah.
1
$(2.3 \%)$
3
9
$(20.9 \%)$
25
$(58.1 \%)$
5
$(11.6 \%)$
$3.70 \quad 0.860$
Sederhana
Tinggi

$\begin{array}{cccccccc}0 & 0 & 1 & 21 & 21 & 4.47 & 0.550 & \text { Tinggi } \\ (0 \%) & (0 \%) & (2.3 \%) & (48.8 \%) & (48.8 \%) & & & \\ & & & & & & & \\ & & & & & & & \\ 0 & 1 & 3 & 22 & 17 & 4.28 & 0.701 & \text { Tinggi } \\ (0 \%) & (2.3 \%) & (7.0 \%) & (51.2 \%) & (39.5 \%) & & & \\ & & & & & & & \end{array}$

Sumber: Soal selidik 2018

Jadual 3 menunjukkan nilai min yang paling tinggi ialah item 4 (Saya berusaha agar semua pelajar saya dapat memahami pelajaran dengan baik). Manakala item yang mempunyai tahap min yang sederhana tinggi ialah item 8 (Saya menghadapi masalah untuk memastikan pelajar dapat menguasai pelajaran), item 7 (Saya sentiasas membuat rujukan untuk menambahkan pengetahuan), item 15 (Saya berpendapat ada pelajar yang memang tidak mempunyai keupayaan untuk menguasai pelajaran dan item 13 (Kadangkala saya merasa kurang bersemangat melihat kebanyakan prestasi pelajar lemah).

Kajian ini menunjukkan guru-guru memiliki sahsiah dan sikap yang positif lagi mulia terhadap pengajaran. Mereka berusaha merancang pengajaran dan melaksanakan secara sistematik di samping berusaha mempertingkatkan kualiti pengajaran. Mereka juga mengambil perhatian terhadap keupayaan pelajar memahami pelajaran serta sentiasa memberi dorongan kepada mereka. Meskipun begitu, guru-guru ini menghadapi cabaran dalam memastikan keberkesanan PdP justeru beranggapan ada segelintir pelajar yang tidak dapat memahami pelajaran.

\section{Amalan Pengajaran Guru}

Jadual 4 di bawah pula menunjukkan nilai min, sisihan piawai dan interpretasi min bagi 39 item dalam konstruk amalan pengajaran guru pada sesi permulaan (8 item), perkembangan (16 item), penutup (9 item) dan penggunaan alat bantu mengajar guru (6 item) di dalam proses PdP. Dapatan kajian berdasarkan konstruk permulaan pengajaran menunjukkan 6 item mencatatkan interpretasi min tinggi dan 2 item pada tahap sederhana tinggi.

Jadual 4: Tahap Permulaan Pengajaran

\begin{tabular}{|c|c|c|c|c|c|c|c|c|c|}
\hline No & Item & STK & TK & KK & $\mathbf{K}$ & SK & Min & $\begin{array}{c}\text { Sisihan } \\
\text { piawai }\end{array}$ & Interpretasi \\
\hline 1. & $\begin{array}{l}\text { Saya memulakan } \\
\text { pengajaran dengan } \\
\text { set induksi yang } \\
\text { telah dirancang. }\end{array}$ & $\begin{array}{c}0 \\
(0 \%)\end{array}$ & $\begin{array}{c}1 \\
(2.3 \%)\end{array}$ & $\begin{array}{c}8 \\
(18.6 \%)\end{array}$ & $\begin{array}{c}22 \\
(51.2 \%)\end{array}$ & $\begin{array}{c}12 \\
(27.9 \%)\end{array}$ & 4.05 & 0.115 & Tinggi \\
\hline 2. & Saya melakukan & 0 & 2 & 8 & 26 & 7 & 3.88 & 0.111 & Sederhana \\
\hline
\end{tabular}




\begin{tabular}{|c|c|c|c|c|c|c|c|c|c|}
\hline & $\begin{array}{l}\text { aktiviti-aktiviti } \\
\text { yang menarik }\end{array}$ & $(0 \%)$ & $(4.7 \%)$ & (18.6\%) & $(60.5 \%)$ & $(16.3 \%)$ & & & Tinggi \\
\hline 3. & $\begin{array}{l}\text { perhatian pelajar. } \\
\text { Saya menepati } \\
\text { waktu setiap kali } \\
\text { memulakan } \\
\text { pengajaran. }\end{array}$ & $\begin{array}{c}0 \\
(0 \%)\end{array}$ & $\begin{array}{c}0 \\
(0 \%)\end{array}$ & $\begin{array}{c}2 \\
(4.7 \%)\end{array}$ & $\begin{array}{c}24 \\
(55.8 \%)\end{array}$ & $\begin{array}{c}17 \\
(39.5 \%)\end{array}$ & 4.35 & 0.087 & Tinggi \\
\hline 4. & $\begin{array}{l}\text { Saya } \\
\text { mementingkan } \\
\text { kepelbagaian dalam } \\
\text { set induksi setiap } \\
\text { kali pengajaran. }\end{array}$ & $\begin{array}{c}0 \\
(0 \%)\end{array}$ & $\begin{array}{c}2 \\
(4.7 \%)\end{array}$ & $\begin{array}{c}4 \\
(9.3 \%)\end{array}$ & $\begin{array}{c}22 \\
(51.2 \%)\end{array}$ & $\begin{array}{c}15 \\
(34.9 \%)\end{array}$ & 4.16 & 0.120 & Tinggi \\
\hline 5. & $\begin{array}{l}\text { Saya mengaitkan } \\
\text { pelajaran dengan } \\
\text { pengetahuan sedia } \\
\text { ada pelajar. }\end{array}$ & $\begin{array}{c}0 \\
(0 \%)\end{array}$ & $\begin{array}{c}0 \\
(0 \%)\end{array}$ & $\begin{array}{c}6 \\
(14.0 \%)\end{array}$ & $\begin{array}{c}20 \\
(46.5 \%)\end{array}$ & $\begin{array}{c}17 \\
(39.5 \%)\end{array}$ & 4.26 & 0.106 & Tinggi \\
\hline 6. & $\begin{array}{l}\text { Saya memastikan } \\
\text { pelajar telah } \\
\text { bersedia untuk } \\
\text { belajar setiap kali } \\
\text { permulaan } \\
\text { pengajaran. }\end{array}$ & $\begin{array}{c}0 \\
(0 \%)\end{array}$ & $\begin{array}{c}0 \\
(0 \%)\end{array}$ & $\begin{array}{c}6 \\
(14.0 \%)\end{array}$ & $\begin{array}{c}24 \\
(55.8 \%)\end{array}$ & $\begin{array}{c}13 \\
(30.2 \%)\end{array}$ & 4.16 & 0.099 & Tinggi \\
\hline 7. & $\begin{array}{l}\text { Saya } \\
\text { mengemukakan } \\
\text { soalan pada } \\
\text { permulaan } \\
\text { pengajaran. }\end{array}$ & $\begin{array}{c}0 \\
(0 \%)\end{array}$ & $\begin{array}{c}3 \\
(7.0 \%)\end{array}$ & $\begin{array}{c}8 \\
(18.6 \%)\end{array}$ & $\begin{array}{c}23 \\
(53.5 \%)\end{array}$ & $\begin{array}{c}9 \\
(20.9 \%)\end{array}$ & 3.88 & 0.125 & $\begin{array}{l}\text { Sederhana } \\
\text { Tinggi }\end{array}$ \\
\hline 8. & $\begin{array}{l}\text { Saya memastikan } \\
\text { pelajar bersedia } \\
\text { setiap kali } \\
\text { pengajaran. }\end{array}$ & $\begin{array}{c}0 \\
(0 \%)\end{array}$ & $\begin{array}{c}0 \\
(0 \%)\end{array}$ & $\begin{array}{c}4 \\
(9.3 \%)\end{array}$ & $\begin{array}{c}24 \\
(55.8 \%)\end{array}$ & $\begin{array}{c}15 \\
(34.9 \%)\end{array}$ & 4.26 & 0.095 & Tinggi \\
\hline
\end{tabular}

Sumber: Soal selidik 2018

Seterusnya, jadual 5 menunjukkan dapatan kajian berdasarkan konstruk perkembangan sesi pengajaran guru. Kesemua item menunjukkan nilai min pada tahap yang tinggi. Item yang mempunyai tahap min yang paling tinggi ialah item 3 (Saya berusaha membetulkan kefahaman setiap pelajar yang bermasalah semasa pengajaran), item 5 (Semasa mengajar saya menerangkan pengajaran dengan jelas agar mudah difahami pelajar), item 6 (Saya menggalakkan pelajar agar mengambil bahagian dalam aktiviti pembelajaran), item 7 (Saya bersemangat mengajar walaupun kepada golongan pelajar lemah), item 12 (Saya meminta setiap pelajar mengulang-ulang bacaan yang telah diajar), item 14 (Saya memberi peluang kepada pelajar untuk aktif dalam pembelajaran), item 9 (Saya dapat mengawal bilik darjah dengan baik semasa mengajar), item 10 (Saya menjawab persoalan pelajar dengan jelas), item 16 (Mengaitkan pelajaran dengan penglaman pelajar), item 13 (Saya menyediakan pengajaran tambahan untuk pelajar yang lemah), item 2 (Kaedah pengajaran saya adalah berbagai-bagai (contoh: kaedah kelas, kumpulan, individu), item 1 (Saya mengajar dengan menggunakan pelbagai teknik pengajaran (contoh: soal jawab, tunjuk cara), item 8 (Saya menyesuaikan kaedah pengajaran dengan minat pelajar semasa mengajar), item 15 (Saya memperbanyakkan sesi soal jawab), item 11 (Saya membuat latih tubi kepada pelajar yang lemah) dan item yang paling rendah ialah item 4 (Semasa mengajar saya memberi penekanan kepada pelajar yang lemah). 
Jadual 5: Tahap Perkembangan Pengajaran

\begin{tabular}{|c|c|c|c|c|c|c|c|c|c|}
\hline No & Item & STK & TK & KK & $\mathbf{K}$ & SK & Min & $\begin{array}{c}\text { Sisihan } \\
\text { piawai }\end{array}$ & Interpretasi \\
\hline 1. & $\begin{array}{l}\text { Saya mengajar } \\
\text { dengan } \\
\text { menggunakan } \\
\text { pelbagai teknik } \\
\text { pengajaran (contoh: } \\
\text { soal jawab, tunjuk } \\
\text { cara). }\end{array}$ & $\begin{array}{c}0 \\
(0 \%)\end{array}$ & $\begin{array}{c}1 \\
(2.3 \%)\end{array}$ & $\begin{array}{c}7 \\
(16.3 \%)\end{array}$ & $\begin{array}{c}21 \\
(48.8 \%)\end{array}$ & $\begin{array}{c}14 \\
(32.6 \%)\end{array}$ & 4.12 & 0.116 & Tinggi \\
\hline 2. & $\begin{array}{l}\text { Kaedah pengajaran } \\
\text { saya adalah } \\
\text { berbagai-bagai } \\
\text { (contoh: kaedah } \\
\text { kelas, kumpulan, } \\
\text { individu). }\end{array}$ & $\begin{array}{c}1 \\
(2.3 \%)\end{array}$ & $\begin{array}{c}1 \\
(2.3 \%)\end{array}$ & $\begin{array}{c}4 \\
(9.3 \%)\end{array}$ & $\begin{array}{c}22 \\
(51.2 \%)\end{array}$ & $\begin{array}{c}15 \\
(34.9 \%)\end{array}$ & 4.14 & 0.131 & Tinggi \\
\hline 3. & $\begin{array}{l}\text { Saya berusaha } \\
\text { membetulkan } \\
\text { kefahaman setiap } \\
\text { pelajar yang } \\
\text { bermasalah semasa } \\
\text { pengajaran. }\end{array}$ & $\begin{array}{c}0 \\
(0 \%)\end{array}$ & $\begin{array}{c}0 \\
(0 \%)\end{array}$ & $\begin{array}{c}2 \\
(4.7 \%)\end{array}$ & $\begin{array}{c}20 \\
(46.5 \%)\end{array}$ & $\begin{array}{c}21 \\
(48.8 \%)\end{array}$ & 4.44 & 0.090 & Tinggi \\
\hline 4. & $\begin{array}{l}\text { Semasa mengajar } \\
\text { saya memberi } \\
\text { penekanan kepada } \\
\text { pelajar yang lemah. }\end{array}$ & $\begin{array}{c}0 \\
(0 \%)\end{array}$ & $\begin{array}{c}0 \\
(0 \%)\end{array}$ & $\begin{array}{c}8 \\
(18.6 \%)\end{array}$ & $\begin{array}{c}27 \\
(62.8 \%)\end{array}$ & $\begin{array}{c}8 \\
(18.6 \%)\end{array}$ & 4.00 & 0.094 & Tinggi \\
\hline 5. & $\begin{array}{l}\text { Semasa mengajar } \\
\text { saya menerangkan } \\
\text { pengajaran dengan } \\
\text { jelas agar mudah } \\
\text { difahami pelajar. }\end{array}$ & $\begin{array}{c}0 \\
(0 \%)\end{array}$ & $\begin{array}{c}0 \\
(0 \%)\end{array}$ & $\begin{array}{c}2 \\
(4.7 \%)\end{array}$ & $\begin{array}{c}25 \\
(58.1 \%)\end{array}$ & $\begin{array}{c}16 \\
(37.2 \%)\end{array}$ & 4.33 & 0.086 & Tinggi \\
\hline 6. & $\begin{array}{l}\text { Saya menggalakkan } \\
\text { pelajar agar } \\
\text { mengambil } \\
\text { bahagian dalam } \\
\text { aktiviti } \\
\text { pembelajaran. }\end{array}$ & $\begin{array}{c}0 \\
(0 \%)\end{array}$ & $\begin{array}{c}0 \\
(0 \%)\end{array}$ & $\begin{array}{c}1 \\
(2.3 \%)\end{array}$ & $\begin{array}{c}28 \\
(65.1 \%)\end{array}$ & $\begin{array}{c}14 \\
(32.6 \%)\end{array}$ & 4.30 & 0.078 & Tinggi \\
\hline 7. & $\begin{array}{l}\text { Saya bersemangat } \\
\text { mengajar walaupun } \\
\text { kepada golongan } \\
\text { pelajar lemah. }\end{array}$ & $\begin{array}{c}0 \\
(0 \%)\end{array}$ & $\begin{array}{c}0 \\
(0 \%)\end{array}$ & $\begin{array}{c}2 \\
(4.7 \%)\end{array}$ & $\begin{array}{c}26 \\
(60.5 \%)\end{array}$ & $\begin{array}{c}15 \\
(34.9 \%)\end{array}$ & 4.30 & 0.085 & Tinggi \\
\hline 8. & $\begin{array}{l}\text { Saya menyesuaikan } \\
\text { kaedah pengajaran } \\
\text { dengan minat } \\
\text { pelajar semasa } \\
\text { mengajar. }\end{array}$ & $\begin{array}{c}0 \\
(0 \%)\end{array}$ & $\begin{array}{c}0 \\
(0 \%)\end{array}$ & $\begin{array}{c}5 \\
(11.6 \%)\end{array}$ & $\begin{array}{c}28 \\
(65.1 \%)\end{array}$ & $\begin{array}{c}10 \\
(23.3 \%)\end{array}$ & 4.12 & 0.089 & Tinggi \\
\hline 9. & $\begin{array}{l}\text { Saya dapat } \\
\text { mengawal bilik } \\
\text { darjah dengan baik } \\
\text { semasa mengajar. }\end{array}$ & $\begin{array}{c}0 \\
(0 \%)\end{array}$ & $\begin{array}{c}0 \\
(0 \%)\end{array}$ & $\begin{array}{c}3 \\
(7.0 \%)\end{array}$ & $\begin{array}{c}27 \\
(62.8 \%)\end{array}$ & $\begin{array}{c}13 \\
(30.2 \%)\end{array}$ & 4.23 & 0.087 & Tinggi \\
\hline 10. & $\begin{array}{l}\text { Saya menjawab } \\
\text { persoalan pelajar } \\
\text { dengan jelas. }\end{array}$ & $\begin{array}{c}0 \\
(0 \%)\end{array}$ & $\begin{array}{c}0 \\
(0 \%)\end{array}$ & $\begin{array}{c}5 \\
(11.6 \%)\end{array}$ & $\begin{array}{c}24 \\
(55.8 \%)\end{array}$ & $\begin{array}{c}14 \\
(32.6 \%)\end{array}$ & 4.21 & 0.097 & Tinggi \\
\hline 11. & $\begin{array}{l}\text { Saya membuat latih } \\
\text { tubi kepada pelajar }\end{array}$ & $\begin{array}{c}0 \\
(0 \%)\end{array}$ & $\begin{array}{c}1 \\
(2.3 \%)\end{array}$ & $\begin{array}{c}6 \\
(14.0 \%)\end{array}$ & $\begin{array}{c}26 \\
(60.5 \%)\end{array}$ & $\begin{array}{c}10 \\
(23.3 \%)\end{array}$ & 4.05 & 0.105 & Tinggi \\
\hline
\end{tabular}


yang lemah.

12. Saya meminta

setiap pelajar mengulang-ulang

bacaan yang telah

diajar.

13. Saya menyediakan

pengajaran

tambahan untuk

pelajar yang lemah.

14. Saya memberi

peluang kepada

pelajar untuk aktif

dalam

pembelajaran.

15. Saya

memperbanyakkan

sesi soal jawab.

16. Saya mengaitkan

pelajaran dengan

pengalaman pelajar

$\begin{array}{cccccccr}0 & 1 & 3 & 23 & 16 & 4.26 & 0.106 & \text { Tinggi } \\ (0 \%) & (2.3 \%) & (7.0 \%) & (53.5 \%) & (37.2 \%) & & & \end{array}$

$\begin{array}{cccccccc}0 & 1 & 3 & 26 & 13 & 4.19 & 0.101 & \text { Tinggi } \\ (0 \%) & (2.3 \%) & (7.0 \%) & (60.5 \%) & (30.2 \%) & & & \end{array}$

$\begin{array}{cccccccc}0 & 0 & 4 & 24 & 15 & 4.26 & 0.095 & \text { Tinggi } \\ (0 \%) & (0 \%) & (9.3 \%) & (55.8 \%) & (34.9 \%) & & & \end{array}$

$\begin{array}{cccccccc}0 & 1 & 5 & 26 & 11 & 4.09 & 0.104 & \text { Tinggi } \\ (0 \%) & (2.3 \%) & (11.6 \%) & (60.5 \%) & (25.6 \%) & & & \\ 0 & 0 & 5 & 26 & 12 & 4.16 & 0.094 & \text { Tinggi } \\ (0 \%) & (0 \%) & (11.6 \%) & (60.5 \%) & (27.9 \%) & & & \\ & & & & & & & \end{array}$

Sumber: Soal selidik 2018

Jadual 6 di bawah menunjukkan nilai min bagi konstruk penutup pengajaran guru. Terdapat 6 item yang mendapati nilai min yang tinggi iaitu item 1 (Saya merumuskan pengajaran yang telah disampaikan), item 7 (Saya berbincang dengan pelajar untuk meningkatkan pelajaran), item 5 (Saya mengenalpasti pelajar yang lemah), item 6 (Saya mengaitkan pelajaran dengan reality kehidupan), item 2 (Saya meminta pelajar menjelaskan isiisi pelajaran), item 3 (Saya membimbing pelajar untuk merumuskan pelajaran).

Manakala item yang menunjukkan sederhana tinggi iaitu item 9 (Saya meminta pelajar menulis kesimpulan pelajaran dalam buku catatan mereka), item 8 (Saya menggalakkan pelajar menilai kelemahan diri sendiri), item 4 (Saya merekod kelemahan setiap pelajar untuk tindakan susulan).

Jadual 6: Tahap Penutup Pengajaran

\begin{tabular}{|c|c|c|c|c|c|c|c|c|c|}
\hline No & Item & STK & TK & KK & $\mathbf{K}$ & SK & Min & $\begin{array}{l}\text { Sisihan } \\
\text { piawai }\end{array}$ & Interpretasi \\
\hline 1. & $\begin{array}{l}\text { Saya merumuskan } \\
\text { pengajaran yang } \\
\text { telah disampaikan }\end{array}$ & $\begin{array}{c}0 \\
(0 \%)\end{array}$ & $\begin{array}{c}1 \\
(2.3 \%)\end{array}$ & $\begin{array}{c}1 \\
(2.3 \%)\end{array}$ & $\begin{array}{c}24 \\
(55.8 \%)\end{array}$ & $\begin{array}{c}17 \\
(39.5 \%)\end{array}$ & 4.33 & 0.098 & Tinggi \\
\hline 2. & $\begin{array}{l}\text { Saya meminta } \\
\text { pelajar } \\
\text { menjelaskan isi-isi } \\
\text { pelajaran }\end{array}$ & $\begin{array}{c}0 \\
(0 \%)\end{array}$ & $\begin{array}{c}1 \\
(2.3 \%)\end{array}$ & $\begin{array}{c}5 \\
(11.6 \%)\end{array}$ & $\begin{array}{c}22 \\
(51.2 \%)\end{array}$ & $\begin{array}{c}15 \\
(34.9 \%)\end{array}$ & 4.19 & 0.112 & Tinggi \\
\hline 3. & $\begin{array}{l}\text { Saya membimbing } \\
\text { pelajar untuk } \\
\text { merumuskan } \\
\text { pelajaran }\end{array}$ & $\begin{array}{c}0 \\
(0 \%)\end{array}$ & $\begin{array}{c}1 \\
(2.3 \%)\end{array}$ & $\begin{array}{c}7 \\
(16.3 \%)\end{array}$ & $\begin{array}{c}26 \\
(60.5 \%)\end{array}$ & $\begin{array}{c}9 \\
(20.9 \%)\end{array}$ & 4.00 & 0.105 & Tinggi \\
\hline 4. & $\begin{array}{l}\text { Saya merekod } \\
\text { kelemahan setiap } \\
\text { pelajar untuk } \\
\text { tindakan susulan }\end{array}$ & $\begin{array}{c}0 \\
(0 \%)\end{array}$ & $\begin{array}{c}1 \\
(2.3 \%)\end{array}$ & $\begin{array}{c}16 \\
(37.2 \%)\end{array}$ & $\begin{array}{c}16 \\
(37.2 \%)\end{array}$ & $\begin{array}{c}10 \\
(23.3 \%)\end{array}$ & 3.81 & 0.126 & $\begin{array}{l}\text { Sederhana } \\
\text { Tinggi }\end{array}$ \\
\hline 5. & $\begin{array}{l}\text { Saya mengenal } \\
\text { pasti pelajar yang }\end{array}$ & $\begin{array}{c}0 \\
(0 \%)\end{array}$ & $\begin{array}{c}0 \\
(0 \%)\end{array}$ & $\begin{array}{c}6 \\
(14.0 \%)\end{array}$ & $\begin{array}{c}19 \\
(44.2 \%)\end{array}$ & $\begin{array}{c}18 \\
(41.9 \%)\end{array}$ & 4.28 & 0.107 & Tinggi \\
\hline
\end{tabular}


lemah

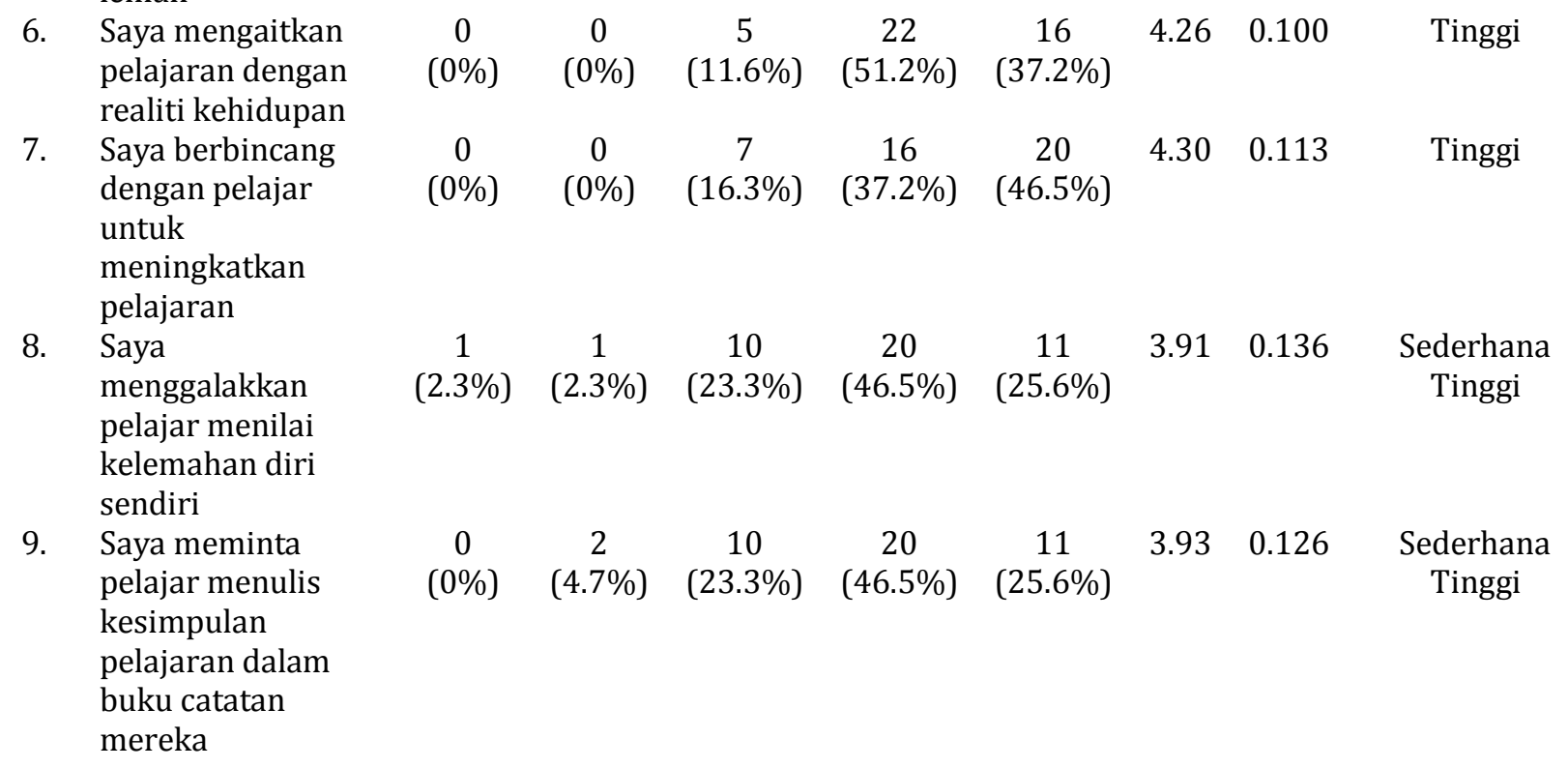

Sumber: Soal Selidik 2018

Dapatan kajian ini menunjukkan guru-guru Pondok Bantan mengamalkan kaedah pengajaran yang amat baik sama ada sebelum, semasa dan penutup proses PdP. Mereka menggunakan pelbagai teknik serta mengubahsuai kaedah pengajaran bagi menarik minat pelajar dan memastikan pelajaran dapat disampaikan secara berkesan. Teknik mengajar yang berkesan adalah apabila murid mudah menerima, menghayati dan boleh mengaplikasi pembelajaran dalam kehidupan seharian (Ab. Halim \& M. Khairul 2010). Skor pengamalan yang tinggi ini dipengaruhi oleh sikap dan akhlak guru. Tingkah laku guru di dalam atau di luar kelas melambangkan keunggulan mereka sebagai guru dan menjadi teladan. Hal ini selari dengan dapatan kajian Hasnah (2000) bahawa pengajaran berkesan dapat dicapai melalui perlaksanaan aktiviti pengajaran yang pelbagai di dalam bilik darjah. Selain itu, ia membuktikan keupayaan guru mengembangkan seluruh potensi pelajar sama ada potensi psikomotor, kognitif atau efektif (Ab. Halim \& M. Khairul 2010). Amalan ini juga dipengaruhi oleh latar belakang guru Pondok Bantan yang majoriti mempunyai kelayakan ijazah pertama selain kelayakan ikhtisas dalam pendidikan dan perguruan.

\section{Penggunaan Alat Bantu}

Jadual 7 di bawah menunjukkan semua item dalam komponen alat bantu mengajar berada pada tahap sederhana tinggi. Item 2 (Saya menyediakan alat bantu mengajar yang menarik untuk pengajaran), item 5 (Alat bantu mengajar dapat membantu pelajar), item 3 (Saya mempelbagaikan penggunaan alat bantu mengajar setiap kali pengajaran), item 6 (Setiap kali mengajar saya menyediakan alat bantu), item 1 (Saya menggunakan alat bantu mengajar yang terkini semasa mengajar) dan item 4 (Saya menggunakan perisian komputer dalam pengajaran).

Jadual 7: Alat Bantu Mengajar

\begin{tabular}{|c|c|c|c|c|c|c|c|c|c|}
\hline No & Item & STK & TK & KK & $\mathbf{K}$ & SK & Min & $\begin{array}{l}\text { Sisihan } \\
\text { piawai }\end{array}$ & Interpretasi \\
\hline 1. & $\begin{array}{l}\text { Saya } \\
\text { menggunakan }\end{array}$ & $\begin{array}{c}4 \\
(9.3 \%)\end{array}$ & $\begin{array}{c}1 \\
(2.3 \%)\end{array}$ & $\begin{array}{c}14 \\
(32.6 \%)\end{array}$ & $\begin{array}{c}17 \\
(39.5 \%)\end{array}$ & $\begin{array}{c}7 \\
(16.3 \%)\end{array}$ & 3.51 & 0.168 & $\begin{array}{l}\text { Sederhana } \\
\text { Tinggi }\end{array}$ \\
\hline
\end{tabular}




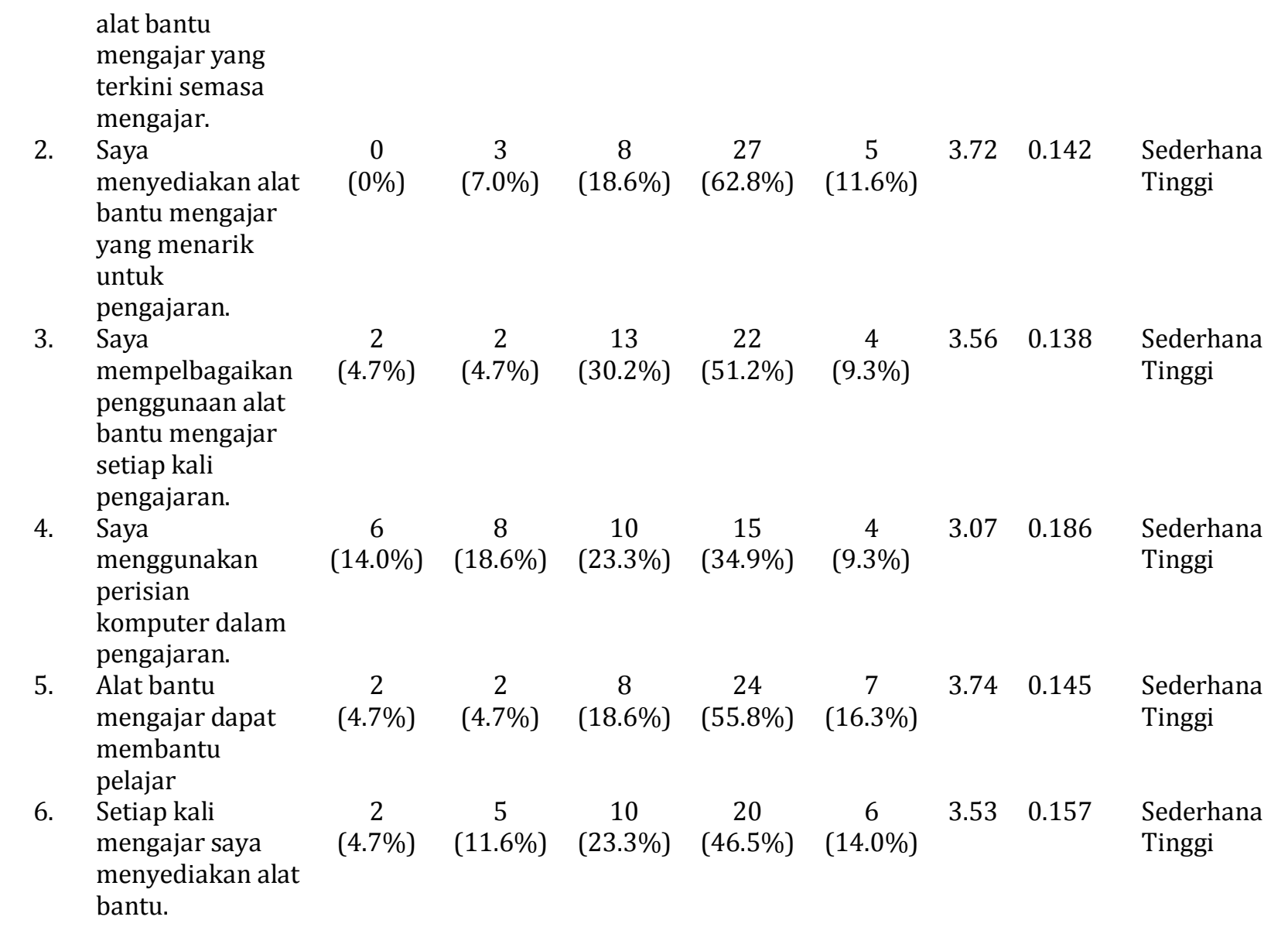

Sumber: Soal selidik 2018

Penggunaan alat bantu mengajar dapat membantu untuk menjadikan pengajaran guru mudah difahami oleh pelajar dan menjadikan pelajar seronok di dalam kelas. Kajian Adel et. al. (2006) mendapati penggunaan alat bantu mengajar membolehkan guru menggunakan kesemua potensi deria agar dapat menarik perhatian pelajar dan memudahkan penguasaan sesuatu kemahiran. Namun begitu, guru-guru Pondok Bantan masih kurang menggunakan bahan bantu mengajar yang terkini termasuk penggunaan komputer. Hal ini berkaitan dengan beberapa faktor antaranya latar belakang kelulusan akademik sebahagian guru dari sistem pondok, keterbatasan kemudahan serta pengajian kitab turath dalam kurikulumnya yang bercirikan metode syarahan dan bacaan teks (Salamiah et. al 2019). Tidak dapat dinafikan bahawa metode tersebut sesuai dan berkesan dalam pengajian tradisional seperti pengajaran hadith bagi menarik minat dan konsentrasi pelajar semasa dalam bilik darjah sebagaimana kajian Qutrennada dan Ahmad Yunus (2017). Masalah ini boleh diatasi melalui penyediaan latihan yang cukup kepada guru sama ada bidang asas pendidikan seperti psikologi dan sosiologi pendidikan dan kemahiran PdP (Abd. Halim \& M. Khairul (2010). Pendedahan kepada kemahiran teknologi maklumat juga amat penting kerana guru-guru kini berdepan dengan pelajar-pelajar generasi Z yang disifatkan oleh Anthony Turner (2015) sebagai generasi yang sudah terdedah kepada digital, internet dan laman sesawang, network sosial dan sumber eletronik di usia sangat muda. Penggunaan teknologi dapat merangsang pelajar memberi pandangan serta mendapat maklumat daripada pelbagai sumber.

Secara keseluruhan kajian ini menunjukkan guru pondok bantan memiliki sahsiah dan sikap yang positif, sentiasa berusaha mempertingkatkan kualiti pengajaran dan meastikan pelajar memahami pelajaran yang disampaikan. Begitu juga mereka menggunakan kaedah 
pengajaran yang amat baik sama ada sebelum, semasa dan penutup proses PdP. Mereka juga menggunakan pelbagai teknik serta mengubahsuai kaedah pengajaran bagi menarik minat pelajar. Beberapa kaedah digunakan seperti soal jawab dan tunjuk cara, kaedah kelas, kumpulan dan individu. Kepelbagaian ini menunjukkan guru bergerak secara aktif dalam proses pengajaran di dalam kelas. Pengamalan pengajaran yang aktif ini dipengaruhi oleh sikap dan akhlak guru. Implikasi kajian ini menunjukkan bahawa guru di Pondok Bantan perlu ditingkatkan kemahiran dalam PdP terutama penggunaan bahan bantu mengajar. Masalah ini boleh diatasi dengan menyediakan latihan yang cukup dan pendedahan kepada penggunaan teknologi bagi merangsang pelajar dan menarik minat pelajar. Sehubungan dengan itu, pengurusan Pondok Bantan disarankan agar menyediakan modul latihan yang komprehensif kepada guru-guru terutama golongan yang tidak mempunyai kelulusan ikhtisas dalam perguruan. Selain itu, prestasi guru dipantau secara berterusan bagi memenuhi piawaian dan hasrat yang ditetapkan oleh pondok. Usaha ini dapat membantu guru menjalankan tugas secara profesional.

\section{Penghargaan}

Artikel ini adalah sebahagian hasil kajian di bawah geran penyelidikan Universiti Kebangsaan Malaysia KRA-2017-033.

\section{References}

Ab. Halim Tamuri \& Mohamad Khairul Azman Ajahury. 2010. Amalan pengajaran guru pendidikan Islam berkesan berteraskan konsep mu'allim. Journal of Islamic and Arabic Education 2(1): 43-56.

Abdul Rahman Laici. 2018. Pendidikan Islam di Pondok Bantan. Interview, 20 December.

Abdullah Ishak. 1989. Sejarah Perkembangan Pelajaran dan Pendidikan Islam. Petaling Jaya: Rahmaniah

Adel M. Abdulaziz, Ahmad Kamel Mohamed \& Muhammad Mustaqim Mohd Zarif. 2006. Panduan dan Bimbingan Guru al-Quran. Kuala Lumpur: iBook Publication Sdn. Bhd.

Anthony D. Medrano. 2007. Islamic Education in Southern Thailand: A Photo Essay. Volume 7, Issue 2, Spring 2007 (Special Edition: Islam in Southeast Asia). Manoa: Universitas Hawai'i.

Anthony Turner. 2015. Generation Z: technology and social interest. The Journal of Individual Psychology 71(2).

Chatthida Yukhong, Thongchai Phuwanatwichit, Charin Mangkhang \& Atchara Sarobol. 2019. Socialization concepts and educational management development to create Muslim citizenship through private Islamic schools in the Southern border provinces of Thailand. International Journal of Islamic Thought 15(June): 27-35.

Faudzinaim Hj. Badaruddin. 2012. Peranan kitab Jawi Tasawuf sebagai medium transmisi ilmu Islam kepada masyarakat Melayu Nusantara. International Journal of Islamic Thought 1: 19-26.

Hasan Madmarn. 2002. Pondok dan Madrasah di Patani. $2^{\text {nd }}$ ed. Bangi. Penerbit Universiti Kebangsaan Malaysia.

Hasnah Nik Hassan. 2000. Pendekatan Pengajaran Tasawur Islam di Sekolah-Sekolah Menengah Kebangsaan di Wilayah Persekutuan. Projek Penyelidikan. Universiti Kebangsaan Malaysia.

Ibrahem Abdullah. 2018. Dr. Surin dan Pondok Bantan. Interview, 20 December.

Kamaruzzaman Bustamam-Ahmad. 2015. Educational practice: lessons to be learned from madrasah and religious schools in contemporary Southeast Asia. Indonesian Journal of Islam and Muslim Societies 5(1): 29-48. 
Karim Harun, Zubir Idris, Muhammad Nursyafiq Zaidi, Ahmed Hafizainol Ahmed Idris. 2019. Pengajaran dan pembelajaran Bahasa Melayu di Pondok Bantan In Farid Mat Zin, Haziyah Hussin \& Rokiah Omar. Jejak Muslim Kota Ligor, pp. 32-42. Bangi: Fakulti Pengajian Islam UKM.

New Mandala. 2013. Islamic education's desperate plight. New Perspective on Southeast Asia. https://www.newmandala.org/desperate-plight-of-islamic-education-in-southernthailand [4 February 2019].

Nor Asyikin Mat Hayin. 2018. Legasi Dr Surin diteruskan adik beradik, Harian Metro, 28 March 2018. https://www.hmetro.com.my/nuansa/. Retrieved: 1 August 2019.

Nunally J.C. 1978. Psycometric Theory. New York: Mc Graw Hill Book Company.

Qutrennada Rosli \& Ahmad Yunus Mohd Noor. 2017. Pengajaran dan pembelajaran hadith di Darul Ulūm Ihyā' Ulūmuddīn Alor Setar Kedah: keberkesanan, metodologi dan persepsi pelajar. Akademika 87(3): 137-149.

Salamiah Ab Ghani, Haziyah Hussin, Mohd Aderi Che Noh, Hamdi Ishak. 2019. Memahami Sistem Pendidikan Islam di Pondok Bantan, Nakhon Si Thammarat. In Farid Mat Zin, Haziyah Hussin \& Rokiah Omar. Jejak Muslim Kota Ligor, pp. 24-31. Bangi: Fakulti Pengajian Islam UKM.

Sofiah Mohamed, Kamarul Azmi Jasmi \& Muhammad Azhar Zailaini. 2016. Akhlak guru dalam pengajaran dan pembelajaran pendidikan Islam. Akademika 86(2): 31-42. 